\title{
O PROJETO POLÍTICO PEDAGÓGICO COMO UM INSTRUMENTO PARA AS RELAÇÕES AFETIVAS E PARA UMA GESTÃo DEMOCRÁTICA NA EMEF PROFESSORA MARIA VALDA BRAGA VALENTE, CAMETÁ/PA
}

\author{
Eliana Miranda Moreira Monteiro ${ }^{1}$ \\ Eliara de Nazaré Mota de Andrade ${ }^{2}$ \\ Márcia de Paula da Silva Gonçalves Medeiros ${ }^{3}$
}

\section{Resumo:}

O presente trabalho tem como objetivo analisar o Projeto Político Pedagógico (PPP) como um instrumento para as relações afetivas e para uma gestão democrática na EMEF. Prof. a Maria Valda Braga Valente do Município de Cametá - Pa. O processo de planejamento e execução do PPP possibilita à escola organizar seu processo pedagógico de forma afetiva, envolvendo a participação de todos os atores do processo educacional, na realização das ações e de avaliação do documento que caracteriza a identidade da escola. A pesquisa traz um panorama dos conceitos ligados ao projeto político pedagógico, o que é, como se expressa, estrutura e amparo legal, bem como definições de relações afetivas e gestão democrática. Para a coleta e análise de dados foram utilizados instrumentos que caracterizam a pesquisa qualitativa. Os dados coletados foram organizados de acordo com método de Análise de Conteúdo apresentado por Bardin (2009). Assim, podemos observar que a EMEF. Prof. a Valda Valente apresenta o PPP como um documento teórico-prático que pressupõe as relações afetivas na escola enquanto processo de democratização.

Palavras-Chave: Projeto Político Pedagógico. Relações Afetivas. Gestão Democrática.

\footnotetext{
${ }^{1}$ Graduada em Pedagogia pela Universidade Federal do Pará (UFPA). Pós Graduada em Psicopedagogia pela Faculdade Internacional de Curitiba (FACINTER). Pós Graduada em Gestão Escolar e Coordenação Pedagógica pela Faculdade de Patrocínio (FAP). Mestranda em Ciências da Educação pela Facultad Interamericana de Ciências Sociales. E-mail: elianammiranda@yahoo.com.br ${ }^{2}$ Graduada em Letras - Português pela Universidade Federal do Pará (UFPA). Graduada em Ciências Naturais pela Universidade do Estado do Pará (UEPA). Graduada em Pedagogia pelo Centro Universitário Internacional (UNINTER). Pós Graduada em Metodologia do Ensino de Biologia e Química pela Faculdade Internacional de Curitiba (FACINTER). Pós Graduada em Educação Especial e Inclusiva Faculdade de Ciências de Wenceslau Braz (FACIBRA). Pós Graduada em Gestão Escolar e Coordenação Pedagógica pela Faculdade de Patrocínio (FAP). Mestranda em Ciências da Educação pela Facultad Interamericana de Ciências Sociales. E-mail: eliaranazareth@yahoo.com.br

${ }^{3}$ Graduada em Pedagogia pela Universidade Federal do Pará (UFPA). Graduada em Serviço Social pelo Centro Universitário Leonardo da Vinci (UNIASSELVI). Pós Graduada em Linguagem e Educação pela Universidade Federal do Pará (UFPA). Pós em Gestão da Administração Pública pela Universidade Castelo Branco (UCB). Pós Graduada em Psicopedagogia com Ênfase em Educação Inclusiva pela Faculdade de Patrocínio (FAP). Pós em Docência do Ensino Superior pela Faculdade de Patrocínio (FAP). Mestranda em Ciência da Educação pela Facultad Interamericana de Ciências Sociales. E-mail: marcinhapmedeiroscameta@hotmail.com
} 


\section{INTRODUÇÃO}

A relevância desse estudo reflete na possibilidade de promover um debate acerca de um Projeto Político Pedagógico de uma escola mediante a sua construção significativa, proporcionando a melhoria da qualidade do ensino, bem como, a promoção de relações afetivas do sujeito no processo de ensino-aprendizagem. Nesse sentido, entendemos que levar esse debate e estudo para a realidade educacional da Escola Municipal de Ensino Fundamental Professora Maria Valda Braga Valente - Município de Cametá - Pará, implica contribuir para com a comunidade em que a escola está inserida, além de orientar outras instituições escolares do município a se proporem não apenas ao debate, mas também ao exercício da prática da autonomia e da gestão democrática.

O projeto político pedagógico mostra a visão macro do que a instituição escolar pretende ou idealiza fazer, seus objetivos, metas e estratégias permanentes, tanto no que se refere às suas atividades pedagógicas, como às funções administrativas. Portanto, o projeto político pedagógico faz parte do planejamento e da gestão escolar, sendo que, ao nosso ver, a questão principal do planejamento é expressar a capacidade de se transferir o planejado para a ação. Assim sendo, compete ao PPP a operacionalização do planejamento escolar, em um movimento constante de reflexão-ação-reflexão.

É válido ressaltar que o Projeto Político Pedagógico, trabalhado por uma dinâmica de relações afetivas, torna-se o principal fruto do planejamento coletivo e pode ser revelador da autonomia da escola ao assumir a sua gestão democrática. Envolve processos de reflexão, de decisões sobre a organização, o funcionamento e a proposta pedagógica da instituição. Segundo Vasconcellos (1995, p. 143) é "um instrumento teórico-metodológico que visa ajudar a enfrentar os desafios do cotidiano da escola, só que de uma forma refletida, consciente, sistematizada, orgânica e, o que é essencial, participativa". É uma metodologia de trabalho que possibilita incentivar a ação de todos os agentes da instituição.

Neste sentido, sendo a afetividade um tema bastante discutido em pesquisas dos campos da educação, a mesma é considerada como necessária em todas as suas dimensões, bem como, sua relevância é de uma amplitude considerável no âmbito escolar, familiar, em qualquer meio em que se desenvolvam relações harmônicas. 
A propósito, compreendemos o ser humano como um ser afetivo, mas que precisa ser afetado até a sua dimensão cognitiva, estando sempre na condição de sujeito numa relação articulada com seu objeto. Dessa forma, a afetividade é vista como um fator de grande relevância para a vivência em sociedade e dinamizá-la no processo de construção de um projeto político pedagógico emerge em uma transformação nos próprios atos afetivos, refletindo com isso nas mudanças das relações sociais, influenciando nas manifestações de uma gestão democrática.

Em síntese, esta pesquisa se constitui numa fonte para fomentar debates e programas em torno da temática em questão, permitindo um olhar aprofundado e teórico sobre o projeto político pedagógico como instrumento das relações afetivas, da gestão democrática e suas contribuições para o cumprimento da função social da escola.

O Capítulo 1, intitulado "Projeto Político Pedagógico", traz um panorama dos conceitos ligados ao PPP, o que é, como se expressa, estrutura e amparo legal. Os autores que fundamentaram este estudo foram Veiga (2004), Gadotti (1994), Vasconcellos (1995), entre outros.

O capítulo 2, intitulado "O PPP e a afetividade como fatores preponderantes de uma gestão democrática" trata da importância das relações afetivas com foco nas ações do projeto político pedagógico para a construção de uma gestão democrática.

O capítulo 3, denominado "Resultados e discussões no contexto da EMEF. Prof. a Valda Valente", apresenta os dados que foram coletados no decorrer da pesquisa no que concerne às relações afetivas e à gestão democrática perante o processo do planejamento e da construção do PPP da escola pesquisada.

\section{Projeto Político Pedagógico}

O Projeto Político Pedagógico, como processo histórico e social, constitui-se naquilo que os educadores produzem nas escolas, como expressão de suas escolhas diante das contradições e dos embates que se apresentam.

De acordo com Vasconcelos (2004), o PPP só será realmente um direito e um dever quando todos os envolvidos nesse processo estiverem cientes de que fazem parte dele, acreditando na sua importância. Nesse pressuposto, ele não será apenas um documento, e sim, poderá ser utilizado como norteador para um trabalho pedagógico, desenvolvido coerentemente entre teoria e prática. 
A importância da escola em construir este documento é reconhecida pela legislação. Assim, o Projeto Político Pedagógico, em âmbito federal, é citado pela Lei de Diretrizes e Bases, Lei 9.394/96 (BRASIL, 1996).

As palavras que compõem o nome do documento ajudam a esclarecer seu significado: é Projeto porque reúne propostas de ação concreta a executar durante determinado período de tempo; é Político por considerar a escola como espaço de formação de cidadãos conscientes, responsáveis e críticos, que atuarão individual e coletivamente na sociedade, modificando os rumos que ela deve seguir e é Pedagógico porque define e organiza as atividades e os projetos educativos necessários ao processo de ensino e aprendizagem.

O PPP de qualidade oportuniza, a todos, participação no processo educacional e compreende a educação como um processo de formação do ser humano, em todas as suas dimensões: conhecimento, afetividade, sexualidade, cidadania e ética. É um documento resultante do planejamento escolar como um todo que deve expressar as orientações gerais da escola, antecipar acontecimentos e envolver estratégias e propostas práticas de ação.

No sentido etimológico a palavra projeto vem do latim projectu, do verbo projicere, que significa se lançar para frente, portanto, a construção de um projeto político-pedagógico na escola significa a busca de mudanças e melhoria no processo de ensino e aprendizagem. Para Gadotti,

\begin{abstract}
todo projeto supõe rupturas com o presente e promessas para o futuro. Projetar significa tentar quebrar um estado confortável para arriscar-se, atravessar um período de instabilidade e buscar uma nova estabilidade em função da promessa que cada projeto contém de estado melhor do que o presente. Um projeto educativo pode ser tomado como promessa frente a determinadas rupturas. As promessas tornam visíveis os campos de ação possível, compreendendo seus atores e autores. (GADOTTI, 1994, p. 579).
\end{abstract}

A palavra projeto traz consigo a ideia de futuro, de vir-a-ser, que tem como ponto de partida o presente (daí a expressão "projetar o futuro"). É extensão, ampliação, recriação, inovação, do presente já construído e, sendo histórico, pode ser transformado, no que diz Gadotti (2000), em um projeto que necessita rever o instituído para, a partir dele, instituir outra coisa, tornar-se instituinte.

Segundo Veiga (2004), o Projeto Político Pedagógico é um instrumento de que a escola lança mão para se propor a lançar para diante em suas ações educativas, buscar um rumo, romper com o presente visando o futuro; é político-pedagógico na 
medida em que é uma ação intencional com um compromisso definido com a formação do indivíduo para um tipo de sociedade.

Por ser um projeto, não está pronto e acabado, uma vez que supõe uma busca constante de alternativas viáveis à efetivação do trabalho pedagógico, exigindo uma atitude de pesquisa e reflexão sobre a realidade cultural do aluno, da escola e das práticas educativas numa perspectiva não excludente.

O projeto político-pedagógico é o elemento que norteia todo o trabalho dos membros da escola. Nele devem estar contidas todas as metas e planejamento do que se pretende e o que deve ser feito para se chegar aonde se quer, buscando assim a construção de uma realidade sólida da educação. Segundo Vasconcelos (2004),

o projeto político-pedagógico é o plano global da instituição. Pode ser entendido como a sistematização, nunca definitiva, de um processo de planejamento participativo, que se aperfeiçoa e se concretiza na caminhada, que define claramente o tipo de ação educativa que se quer realizar. É um instrumento teórico - metodológico para a intervenção e mudança da realidade. É um elemento de organização e integração da atividade prática da instituição neste processo de transformação. (VASCONCELOS, 2004, p. 169).

O PPP não deve ser elaborado apenas para atender a uma exigência burocrática. O mesmo é contínuo, pode ser reformulado quando necessário e, principalmente, não deve ser guardado e esquecido. É ferramenta fundamental a ser usada como guia das atividades pedagógicas, colocando em prática ações propostas, podendo a escola avaliar continuamente estas ações, e futuramente sanar as dificuldades encontradas no processo de ensino e aprendizagem.

O projeto político pedagógico é dividido em três dimensões: a dimensão pedagógica que aborda a visão, valores e missão da escola, os subprojetos, o currículo, a avaliação do processo ensino aprendizagem, suporte ao corpo docente, entre outros; a dimensão comunitária que aborda a participação de toda a comunidade escolar no processo educativo da escola; e a dimensão administrativa que aborda as questões relacionas a parte financeira, dos funcionários, dos horários, enfim a parte mais burocrática da escola.

Com cada uma dessas dimensões bem definidas e bem trabalhadas, o PPP torna-se abrangente a todos os setores da escola, considerando sempre que o foco principal da Unidade Escolar é o desenvolvimento pleno do aluno.

Nesse sentido, a construção/ressignificação do "projeto político-pedagógico pressupõe três atos distintos, considerados essenciais na sua elaboração, os quais 
se relacionam entre si" (VEIGA, 1998, p.23). Esses três atos deverão ser descritos contemplando-se a realidade, a utopia e as metas da escola expressas nas reflexões e nas sistematizações do grupo. São eles: ato situacional, ato conceitual e ato operacional, vejamos cada um desses conceitos:

a. O ato situacional compreende a análise e a sistematização da realidade, a descrição do contexto em que a escola se insere, seus problemas, desafios e utopias. Pode ser elaborado pelo grupo respondendo à seguinte questão: "como compreendemos/vemos/sentimos o mundo atual?" (VASCONCELOS, 1995, p.154).

b. $O$ ato conceitual ou doutrinal expressa a concepção de mundo, de sociedade, de homem, de educação etc. É o referencial teórico que aponta a utopia dos educadores dos pontos de vista político e pedagógico. Deve-se responder às seguintes questões na descrição desse marco: "Que tipo de sociedade queremos construir? Qual a finalidade que queremos para a escola? Que papel desejamos para a escola em nossa realidade?" (VASCONCELOS, 1995, p.154).

c. $\mathrm{O}$ ato operacional ou operativo refere-se ao detalhamento do que vai ser feito, incluindo periodicidade, programação, abrangência etc. É a definição do que é necessário e possível fazer para diminuir a distância entre o que a "escola é (marco situacional) e o que a escola gostaria de ser (marco conceitual). É a proposta de ação, a "tomada de posição quanto às grandes linhas de ação" (VASCONCELOS, 1995, p.155).

Ao se considerar esses três atos, construiremos/ressignificaremos um projeto político pedagógico em harmonia com a história e a identidade da instituição, perguntando: que face tem a nossa escola? O texto reproduzido abaixo complementa e resume muito bem o que foi dito aqui de importante na construção de um projeto político pedagógico:

O projeto pedagógico não é uma peça burocrática e sim um instrumento de gestão e de compromisso político e pedagógico coletivo. Não é feito para ser mandado para alguém ou algum setor, mas sim para ser usado como referência para as lutas da escola. É um resumo das condições e funcionamento da escola e ao mesmo tempo um diagnóstico seguido de compromissos aceitos e firmados pela escola consigo mesma - sob o olhar atento do poder público. (FREITAS et al., 2004, p. 69)

O projeto político-pedagógico, por ser o documento de natureza democrática, deve contar sempre com a participação dos docentes, gestores e comunidade escolar 
em geral na sua elaboração, desenvolvimento e aplicação, servindo de base para que a gestão democrática seja instaurada de fato na escola.

É evidente que tais intuitos, em estados e municípios como o nosso, só poderão decorrer de políticas definidas e implementadas em nível macro e direcionadas a melhoria da escola e do ensino que ela oferece. A Lei de Diretrizes e Bases da educação Nacional (LDB) de 9394/96 fornece, nesse propósito, o aporte legal para que a escola se organize, de forma autônoma e variada, na elaboração da sua proposta pedagógica.

No artigo 12, inciso I, que se pode denominá-lo de "artigo da escola", a Lei oferece aos estabelecimentos de ensino a incumbência de elaborar e executar sua proposta pedagógica. Ainda nesse mesmo artigo, inciso VII, define-se como incumbência da escola informar os pais e responsáveis sobre a frequência e o rendimento dos alunos, bem como sobre a execução de sua proposta pedagógica.

No artigo 13, inciso I, chamado o "artigo dos professores", aparecem como incumbências desse segmento, entre outras, as de participar da elaboração da proposta pedagógica do estabelecimento de ensino. E no inciso II, elaborar e cumprir plano de trabalho, segundo a proposta pedagógica do estabelecimento de ensino.

Por fim, no artigo 14, em que são definidos os princípios da gestão democrática, o primeiro deles é a participação dos profissionais da educação na elaboração do projeto político pedagógico da escola.

Nessa perspectiva, é válido salientar que a Lei de Diretrizes e Bases da Educação Nacional detalha aspectos pedagógicos da organização escolar, o que demonstra com propriedade o valor atribuído a essa questão pela atual legislação educacional.

Portanto, a escola, enquanto centro das políticas educativas, tem, assim, de construir a sua autonomia a partir da comunidade em que se insere dos seus problemas e potencialidades, contando com uma nova atitude da administração central, regional e local, que possibilite uma melhor resposta aos desafios da mudança.

\section{O PPP e a afetividade como fatores preponderantes de uma gestão democrática}


O projeto político pedagógico se constitui como um documento teórico-prático elaborado coletivamente pelos sujeitos da escola, para isso entendemos que essa construção necessita de uma relação recíproca de aceitação, respeito, acolhimento, no ambiente em que se encontra, apropriando-se da afetividade.

Ao fazer uma análise da relevância do PPP, Carvalho (2004) relata que "o projeto político-pedagógico pode ser considerado como a carteira de identidade da escola, evidenciando os valores que cultua, bem como o percurso que pretende seguir em busca de atingir a intencionalidade educativa".

Quaisquer tipos de relação em um meio social são modos de afeto que nos são apresentados e externados pela comunicação verbal ou não verbal e vão se constituindo como um elemento indispensável na formação de identidade do sujeito. Em Vygotsky (1991), encontramos a defesa de que a construção do conhecimento pela constituição do sujeito, refletida nas suas formas de agir, acontece pelo constante processo dialético nas interações entre o "EU" e o "OUTRO", como um elo interdependente, o que lhes permitirá apropriar-se de práticas culturais já instituídas, e será a partir dessas práticas que se constituirão a base dos vínculos afetivos que se apresentarão na sociedade em vários formatos.

Sendo assim, conceituar coerentemente afetividade é uma tarefa difícil, tarefa vista como uma problemática historicamente polêmica pelos estudiosos da psicologia, pelo fato de não existir uma definição de consenso entre os adeptos do assunto e que chegue a um resultado sólido nos estudos. Muitos autores já conseguiram apresentar a natureza e a origem, mas não obtiveram êxito em chegar a um conceito definitivo, uma vez que, vários conceitos já foram elaborados por diferentes abordagens psicológicas. Em seus estudos psicológicos, Vygotsky tematizou sobre o afetivo e o cognitivo.

\footnotetext{
A forma de pensar, que junto com o sistema de conceito nos foi imposta pelo meio que nos rodeia, inclui também nossos sentimentos. Não sentimos simplesmente: o sentimento é percebido por nós sob a forma de ciúme, cólera, ultraje, ofensa. Se dizemos que desprezamos alguém, o fato de nomear os sentimentos faz com que estes variem, já que mantêm uma certa relação com nossos pensamentos. (1996, p. 68).
}

Para isso, o autor destaca-se por apresentar conceitos mais precisos, parte da ideia de que é prioridade fazer uma análise da atividade humana como característica essencial para a constituição do seu psiquismo como o eixo norteador para as 
descobertas de explicações teóricas e metodológicas do afetivo-cognitivo para a formação psicológica do sujeito, necessária para o desenvolvimento humano.

Para falar de afetividade é necessário primeiro conhecer alguns conceitos da psicologia sobre o afeto. Na visão dos seguintes autores:

\begin{abstract}
A análise de unidade indica o caminho para a solução desses problemas de importância vital. Demonstra a existência de um sistema dinâmico de significados em que o afetivo e o intelectual se unem. Mostra que cada ideia contém uma atitude afetiva transmutada com relação ao fragmento da realidade ao qual se refere. Permite-nos ainda seguir a trajetória que vai das necessidades e impulsos de uma pessoa até a direção específica tomada por seus pensamentos, e o caminho inverso, a partir de seus pensamentos até 0 seu comportamento e a sua atividade. (VYGOTSKY, apud REGO, 2014, p. 121).
\end{abstract}

Dessa forma, a afetividade para o autor está presente em qualquer ideia de cunho emocional ou intelectual, mostrando que as ideias podem ser expressas em uma atitude afetiva modificada, onde tanto o emocional quanto o intelectual tornamse uma necessidade para se constituir o ensino aprendizagem no processo de desenvolvimento da capacidade do ser humano de pensar e compreender.

Sob a ótica do desenvolvimento humano, na presença de uma mutante diversidade, Vygotsky vem dizer que o ser humano se constitui nas e pelas relações. No entanto, entender o afeto perpassa primeiro pelo reconhecimento das identidades que se apresentam nos campos das relações como resultados dos modos de se expressar, pensar e sentir de cada um, para efetivamente entendermos a afetividade em sua totalidade.

Nessa sequência, a escola vem ser um espaço de relações sociais intensas, que enfatiza como determinantes os aspectos culturais, históricos e sociais, e que o surgimento dessa abordagem veio dar uma ressignificação na visão afetiva do sujeito, considerando que as interações vivenciadas no âmbito social têm o poder de afetar o desenvolvimento do ser humano. Partindo da ideia de que o PPP não nasce pronto, e que é pela relação com o outro que vai lhe fazer construtor daquilo que já é conhecido e dinamizado em seu meio, constituindo-se com isso um documento, que configura a identidade histórico cultural do ambiente escolar.

Nessa perspectiva, cabe à instituição escolar a função de valorização da identidade de todos os sujeitos que constituem a comunidade escolar sob a ótica de sua diversidade. E essa afetividade é uma forma de relacionamento com o outro e com o mundo. Logo, ela é a responsável na constituição de uma relação harmônica e cooperativa entre os sujeitos. Para Vygotsky, quando a afetividade está presente nos 
objetivos das ações da escola, obtêm-se resultados satisfatórios onde teremos a afetividade proporcionando aprendizagens significativas.

A afetividade irá se apresentar com suas características próprias, será caracterizada a partir de suas construções como membra da identidade de cada pessoa. Dessa forma, se ela está presente na constituição do ser humano, logo, se apresenta nas relações tecidas nas interações sociais. A partir dessas considerações, ponderamos a educação escolar como uma entidade responsável na formação de cada sujeito, podendo compreender que a afetividade se externa dentro de uma instituição escolar através das relações entre os atores sociais da escola, porque é justamente nessas relações interpessoais que a afetividade se apresenta com características bem diversificadas.

Dessa forma, a afetividade se encaixa como uma das características da gestão democrática, pois é através dela que conseguimos expressar e melhorar nossas ideias e opiniões, e a escola entra como um ponto bastante favorável, pois é nela que unem-se diferentes culturas, propiciando o desenvolvimento do respeito ao próximo, de opinar e lutar a favor de seus direitos e ser capaz de desenvolver de forma prazerosa seus deveres.

Outro passo muito importante para que a gestão democrática ocorra é a construção do Projeto Político Pedagógico da escola. Ele será o instrumento que definirá as relações entre a escola e a comunidade, mediante explicitação dos princípios, objetivos educacionais, do método de ação e das práticas que serão adotadas.

O Projeto Político Pedagógico é considerado um instrumento norteador da gestão democrática, uma vez que ao ser elaborado de forma conjunta, abre as portas da escola para que gestores, pais, alunos e todos os funcionários tenham voz e participem da construção de uma sociedade mais crítica e participativa.

É muito importante para a construção da gestão democrática, a escola estar aberta à comunidade, para que esta participe das atividades, vivenciando a realidade onde a escola está inserida, não só no que diz respeito à educação, mas também em ações que beneficiem o conjunto da comunidade em geral.

Tezani (2004) afirma que na gestão democrática é preciso eliminar a cultura individualista que visa à fragmentação das decisões e se baseia em estruturas burocráticas, formais e hierarquizadas. Por se tratar de um processo que visa à mudança de atitudes e de valores, existem vários desafios que se apresentam a essa 
proposta, tanto em relação aos conflitos que a permeiam como à lentidão com que esse processo se realiza. Faz-se necessário estabelecer diálogos afetivos que busquem o conhecimento e a mediação dos conflitos.

Nesse sentido, em cada ação e relacionamento da instituição escolar no processo da construção do projeto político pedagógico, é necessário aliar teorias sobre afetividade e gestão democrática com a realidade concreta da escola no quesito relações humanas.

\section{RESULTADOS E DISCUSSÕES NO CONTEXTO DA EMEF. PROF. a VALDA VALENTE}

A pesquisa teve como pretensão analisar os dados que foram coletados no que concerne às relações afetivas e à gestão democrática perante o processo do planejamento e da construção do PPP na Escola Municipal de Ensino Fundamental "Professora Maria Valda Braga Valente", partindo da investigação das relações afetivas entre os sujeitos que participam, direta ou indiretamente, no processo de elaboração/ressignificação do Projeto Político Pedagógico: gestão escolar, professores, funcionários, pais ou responsáveis, alunos.

Adentrando primeiramente no lócus da pesquisa, os presentes dados foram extraídos da E.M.E.F Professora Maria Valda Braga Valente, localizada na Travessa São Joaquim, s/non, bairro da Primavera, no Município de Cametá. O bairro está localizado na periferia da cidade de Cametá, e teve sua formação com o loteamento de terras oriundas de um imigrante japonês. Esse bairro se constituiu de pessoas que se deslocaram da zona rural e ribeirinha do município, em busca de uma vida melhor. Atrelados a todos esses dados nos deparamos com a realidade onde os sujeitos se encontram.

No ano de 2019, período de realização da pesquisa, a EMEF. Prof. ${ }^{\text {a }}$ Maria Valda Braga Valente é considerada de médio porte e possui cerca de 641 alunos matriculados, com turmas funcionando em três turnos: manhã, intermediário e tarde, atendendo as seguintes modalidades de ensino: Educação infantil e Ensino Fundamental I ( $1^{\circ}$ ao $5^{\circ}$ ano).

O atual Projeto Político Pedagógico da EMEF. Prof. ${ }^{a}$ Maria Valda Braga Valente direcionou-se num roteiro de trabalho apresentado em uma palestra e oficina para a sua ressignificação, datadas, respectivamente, em 25 de março e 08 de abril 
de 2017, ambos os eventos realizaram-se com a colaboração de uma palestrante da Secretaria Municipal de Educação de Cametá - SEMED. Posteriormente, a dinâmica para ressignificação do PPP foi feita em grupos de trabalho envolvendo todos os atores escolares. Após o planejamento escolar decidiu-se reconstruir e ressignificar o Projeto
Político Pedagógico (PPP) baseado no processo da gestão democrática,
refletindo coletivamente sobre a participação, a função social da escola, o
currículo e a prática pedagógica. A decisão de ressignificar o Projeto Político
Pedagógico surgiu, pois, o PPP existente, já tinha um tempo que fora
construído e a maioria da comunidade escolar não o conhecia, pois não havia
participado de sua elaboração. Assim, percebeu-se a necessidade de
reelaborar o PPP da escola, uma vez que ele é o instrumento norteador da
escola, visando a sua qualificação, garantindo assim, a contextualização das
ações administrativas e pedagógicas. (PPP - EMEF. VALDA VALENTE,
2018, P.6)

O documento Projeto Político Pedagógico da EMEF. Prof ${ }^{a} M^{a}{ }^{a}$ Valda Braga Valente está organizado da seguinte maneira: Introdução; Justificativa; Identificação e Caracterização da Escola; Atos Legais; Histórico da Escola; Estrutura Física; Função Social da Escola; Objetivos, Princípios e Finalidades, Ato Situacional; Ato Conceitual e Ato Operacional.

Ao analisar o PPP em questão, percebeu-se que está estruturalmente em consonância com legislação vigente, especialmente, com a Lei de Diretrizes e Bases da Educação Nacional № 9.394/1996, apresentando especificidades quanto à estruturação do processo pedagógico com características próprias e de acordo com as necessidades e anseios da comunidade escolar.

Além disso, sua estrutura contempla os três atos distintos - ato situacional, ato conceitual e ato operacional - que de acordo com Veiga (1998) são considerados essenciais na sua elaboração. Esses três atos estão sendo descritos, no processo de ressignificação da escola, contemplando a realidade, a utopia e as metas da escola expressas nas reflexões.

De acordo com as informações cedidas pelos entrevistados, no processo de construção e ressignificação do Projeto Político Pedagógico, percebemos que a concepção adotada na EMEF Maria Valda Braga Valente é de natureza democrática, afetiva e participativa, pois a escola vem se esforçando em garantir a presença de todos os segmentos que compõem a comunidade escolar, até mesmo a categoria dos alunos, cuja faixa etária contempla crianças de, no máximo, 10 anos.

Como é possível perceber, a pesquisa contemplou 5 categorias (Gestão, Professores, Funcionários, Alunos e Pais), totalizando 9 entrevistas. 
Luck (2010) afirma que a participação pode ser caracterizada

pela força da atuação consciente pela qual os membros de uma unidade social reconhecem e assumem seu poder de exercer influência na determinação da dinâmica dessa unidade, de sua cultura e de seus resultados, poder esse resultante de sua competência e vontade de compreender, decidir e agir sobre questões que lhes são afetas, dando-lhe unidade, vigor e direcionamento firme. (LUCK, 2010, p. 21).

Analisando Luck (2010), concordamos que a efetivação da função essencial da escola requer estratégias e mediações pedagógicas sensíveis e afetivas às necessidades da comunidade escolar. Emerge daí, como fundamento da gestão democrática, a participação de representantes dos diversos setores da escola.

É possível perceber, portanto, que os sujeitos neste espaço escolar são lançados para interagirem e socializarem o que há de mais diverso e rico dentro de si, que é a cultura, embora esta seja considerada a mola propulsora inacabada presente nos palcos das relações e interações, ou seja, a cada dia ela se submete a um processo contínuo de construção e reconstrução ao longo dos diferentes contextos históricos.

Adentrando nas relações afetivas em um ambiente escolar, mais

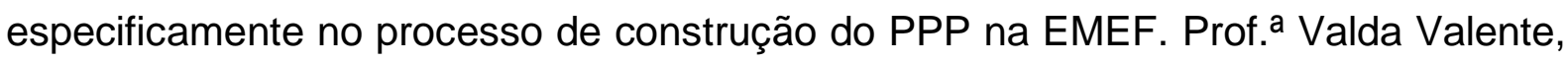
a percepção dos afetos entre todos os sujeitos envolvidos é refletida espontaneamente pela introspecção subjetiva que cada um expõe perante demonstrações e atitudes como sentimentos e experiências já vividas.

\section{CONSIDERAÇÕES FINAIS}

Observamos no contexto escolar da EMEF. Prof. ․ Maria Valda Braga Valente que quando as relações afetivas estão presentes na construção do projeto político pedagógico, é possível perceber uma forma estratégica de inserir a comunidade no processo decisório da escola, e a gestão democrática passa a ser uma prática presente na escola que procura deixar de lado as práticas autoritárias que estão em vigor na sociedade, assumindo uma postura de participação e emancipação.

No que compete em como a gestão escolar planejou e executou a elaboração do Projeto Político Pedagógico junto à comunidade escolar, ressaltamos que a mesma esforçou-se em concretizar a gestão democrática, pois vimos a organização de reuniões e de grupos de estudos abrangendo o envolvimento de todos os atores da 
escola: gestores, professores, alunos, pais e demais funcionários na realidade educacional da EMEF. Valda Valente, pois não se pode esperar que apenas os segmentos escolares tomem consciência da importância da participação, é preciso criar condições e mecanismos afetivos que favoreçam a gestão participativa, e nesse sentido, a referida instituição de ensino oportuniza o exercício afetivo da autonomia à medida que compartilha responsabilidades, e consequentemente, os resultados do processo de ensino e aprendizagem.

A afetividade passou a constituir a palavra de ordem perante as relações e interações dentro de uma escola democrática. Essas relações harmônicas vão sendo construídas no dia-a-dia por todos os educadores e comunidade. E, neste contexto da EMEF. Valda Valente, as relações afetivas constituem uma ferramenta de uma gestão democrática que oportuniza a participação de todos os atores na tomada de decisões, fomentando a avaliação dos resultados e direcionando o olhar de todos para 0 planejamento das ações, atividades e projetos a serem desenvolvidos pela escola.

Neste sentido, é necessário perceber-se como um eterno aprendiz para poder relacionar-se comprometido no cuidado com o outro. Do ponto de vista de Vygotsky, a afetividade não se resume à emoção, mas também na permissividade do ser humano de ser afetado pelo outro, uma vez que somos socialmente construídos nas e pelas relações.

Ponderamos aqui a necessidade de manter e diversificar na escola a promoção constante das relações afetivas, uma vez que, pelos ensinamentos de Vygotsky, constatamos que os laços afetivos dos sujeitos dependem da sua relação social.

Assim, pelo conjunto da pesquisa realizada, podemos observar que a EMEF.

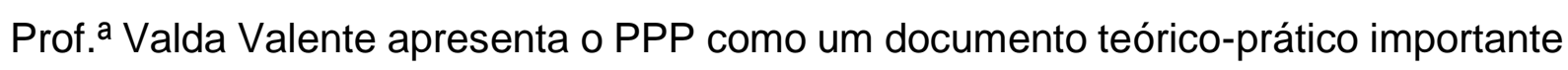
e necessário para a escola por se configurar como um elemento que pode garantir a autonomia pedagógica, administrativa e financeira dela, bem como ser norteador das práticas cotidianas e como elemento capaz de assegurar a gestão democrática e a participação dos envolvidos no processo educacional.

Dessa forma, embora essenciais, não são os termos da pedagogia ou as metodologias que definem a relevância da escola, mas sim as ações estabelecidas com todos os atores que participam dessa instituição de ensino em torno de um objetivo comum. Ressalta-se, assim, a importância do PPP como um instrumento de fortalecimento das relações afetivas e da gestão democrática, contribuindo para a consolidação da qualidade do ensino público. 


\section{REFERÊNCIAS}

BRASIL, Congresso Nacional. Lei de diretrizes e bases da educação nacional Lei N. 9394 de 20 de dezembro de 1996. Brasília: Departamento de Imprensa Nacional (Diário Oficial da União) DF1996.

CAMETÁ. Secretaria Municipal de Educação. Projeto Político Pedagógico - EMEF. Professora Maria Valda Braga Valente. Cametá/Pará: Secretaria Municipal de Educação: 2018. 118 p.

CARVALHO, R. E. Educação Inclusiva: com os pingos nos is. 3. ed. Porto Alegre: Mediação, 2004.

FREITAS, L. C. et al. Dialética d a inclusão e da exclusão: por uma qualidade negociada e emancipadora nas escolas. In: Escola Viva: elementos para a construção de uma educação de qualidade social. GERALDI, C. M. G.; RIOLFI, C. R.; GARCIA, M.F. Campinas: Mercado de Letras Edições e Livraria Ltda., 2004.

GADOTTI, Moacir. Pressupostos do projeto pedagógico. CONFERÊNCIA NACIONAL DE EDUCAÇÃO PARA TODOS, 1, 1994. Anais ... Brasília: MEC, 1994.

GADOTTI, Moacir. Perspectivas atuais da educação. Porto Alegre: Artes Médicas, 2000.

LUCK, Heloísa. A gestão participativa na escola. Rio de Janeiro. Vozes, 2010.

REGO, Tereza Cristina. Vygotsky. Uma Perspectiva histórico-Cultural da educação. 25. Ed. - Petrópolis, RJ: Vozes, 2014.

TEZANI, T. C. R. Os caminhos para a construção da escola inclusiva: a relação entre a gestão escolar e o processo de inclusão. Dissertação - Universidade Federal de São Carlos, São Carlos, 2004.

VASCONCELOS, Celso Santos. Planejamento: plano de ensino-aprendizagem e projeto educativo - elementos metodológicos para elaboração e realização. São Paulo: Libertad, 1995.

VASCONCELLOS, C. S. Projeto político-pedagógico: educação superior. Campinas: Papirus, 2004.

VEIGA, I. P. A.; RESENDE, L. M. G. (orgs.). Escola: espaço do projeto político pedagógico. Campinas: Papirus, 1998.

VEIGA, Ilma Passos Alencastro. Projeto político-pedagógico da escola: uma construção possível. In: Projeto político-pedagógico da escola: uma construção coletiva. 17. ed. São Paulo: Papirus 2004.

VYGOTSKI, L. S. A formação social da mente. São Paulo: Martins Fontes, 1996.

VYGOTSKY, L. S. Pensamento e Linguagem. São Paulo: Martins Fontes, 1996. 